AROUEOLOGÍA Y SOCIEDAD

№ 27, 2014: 29-36

ISSN: 0254-8062

RECIBIDO: FEBRERO DE 2014

ACEPTADO: MAYO DE 2014

\title{
EL PROCESO DE CREACIÓN ARTÍSTICA EN EL ANTIGUO PERÚ
}

\author{
Alba ChOQue Porras \\ UNIVERSIDAD NACIONAL MAYOR DE SAN MARCOS \\ bendecida2102 @gmail.com
}

\section{RESUMEN}

El presente artículo brinda un panorama del proceso de creación de las diversas piezas de arte en el Antiguo Perú. A lo largo del desarrollo de la cultura peruana hay innegable presencia de la especialización de una minoría dedicada a las labores artísticas, que debió estar en un nivel intermedio en la estructura social. Debido al volumen y calidad de su producción, existieron artistas dirigentes y artistas reproductores de dedicación total a estas tareas, puesto que sus obras eran dirigidas para el consumo local y para el intercambio. Dado que la pieza artística del Antiguo Perú no tuvo como fin ser objeto de contemplación, dichas creaciones vienen a ser obras de culto plásticas, arte comprometido con un pensamiento ideológico; cuyo proceso habría pasado una serie de pasos que resolverían la representación formal y simbólica.

PalabRas Clave: Creación artística, Antiguo Perú, arte.

\begin{abstract}
This article provides an overview of the creating process of art in Ancient Peru. Throughout the development of Peruvian culture is undeniable presence of a minority specialization dedicated to artistic work, which should be at an intermediate level in the social structure. Due to the volume and quality of production, there were leaders artists and artists who copy, of total dedication to these tasks, because their deeds were intended for local consumption and for exchange. The art work in Ancient Peru was not meant to be an object of contemplation, these creations come to be works of cult plastic, art committed to ideological thinking, which process would have passed a series of steps to solve formal and symbolic representation.
\end{abstract}

KeYwords: Artistic creation, Ancient Peru, art.

\section{INTRODUCCIÓN}

En los pueblos del antiguo Perú, el hombre divinizó el poder devastador de los fenómenos naturales, y al mismo tiempo les dio un carácter animista; se creía que los fenómenos telúricos, junto a las montañas, lagunas, ríos, árboles, etc., poseían una fuerza sobrenatural, y que ciertos animales y entidades celestiales podían contrarrestar o dominar las fuerzas de la naturaleza. Así, toda la naturaleza estuvo personificada en base a formas y expresiones, personajes que interactúan en la vida real con la celestial e infrahumana; deidades y seres cuyos actos se entremezclan con los hechos cotidianos de los hombres. 
Los dioses andinos eran a su vez dioses del sustento, los que proveían a la humanidad los recursos y condiciones para sobrevivir, a ellos se les debía una serie de 'pagos' en base al rito y ofrendas sagradas, como obras plásticas de gran envergadura o variadas piezas especialmente preparadas para el culto, obras visuales trasmisoras de conocimiento (Kauffmann 2011: 245-289).

Así, por más de cuatro mil años, antes de la llegada del hombre europeo a tierras donde se gestó la civilización del antiguo Perú, diversas expresiones artísticas se desarrollaron, explicando mitos, leyendas e historias, en los cuales se sustentaba el origen y el por qué del mundo en el cual residía. Cada cultura, cada civilización o sociedad organizada manifestó sus pensamientos a través de la forma plástica, bajo diversas expresiones arquitectónicas, escultóricas, textiles, en cerámica, orfebrería, grabado, etc. Rebeca Carrión manifestaba: «La religión en los pueblos precolombinos de América constituye el fundamento básico de elaboración de su cultura, influyendo en la formación de la vida social, económica e intelectual de los indios» (Carrión 2005: 15).

Arte y religión estuvieron enlazados en el antiguo Perú, donde la obra de arte se convirtió en un medio de comunicación visual, fue a través de la imagen y el símbolo como se trasmitieron las ideas y conceptos, ideas religiosas y, por ende, políticas de una elite teocrática. Al mismo tiempo, cada pieza elaborada con esmero por artesanos (productores) y artistas (dirigentes creadores) se convertía en la plasmación de la propia deidad y en otros casos en un canal o conexión entre el oferente y la divinidad misma.

\section{Los estudios sobre el arte en el antiguo Perú}

Al revisar la bibliografía peruana, encontramos que aún no se ha profundizado en investigaciones acerca del proceso de creación artística en el antiguo Perú, a pesar de la enorme calidad y cantidad de investigaciones arqueológicas, históricas, antropológicas y otras, efectuadas por diversos especialistas. Se ha escrito sobre la historia, la arqueología de tal o cual cultura, pero no se ha analizado los pormenores del proceso de creación del arte y en algunos casos ni siquiera se han considerado como artísticas las manifestaciones plásticas del Perú ancestral.

Sin embargo, es bueno destacar los trabajos pioneros realizados por el pintor y escritor Felipe Cossío del Pomar en el Arte del Perú precolombino de 1949, quien indica: «el estudio del arte en la América precolombina se ha llevado a cabo, casi siempre, deductivamente, por hombres de ciencia, no por artistas. Hasta ahora se ha hecho sólo labor de Arqueología» (Cossío 1949: 15). Por su parte, en 1967 el historiador de arte peruano Francisco Stastny en su Breve historia del arte en el Perú, denomina artistas a los artífices de las obras plásticas de diversas culturas, sólo por citar un ejemplo Stastny menciona: «El pintor Mochica da la impresión de haber sido mucho más libre en el uso de sus motivos que el artista Nazca y haber tenido una mayor variedad iconográfica» (Stastny 1967: 19). Ya desde esa fecha Stastny da la categoría de artista a los creadores de las obras plásticas.

Otro libro de importancia será Fuentes para el estudio del arte peruano precolombino de María Luisa Saco (1978). La doctora Saco fue una de las pioneras en el estudio y rescate de nuestro arte peruano. Fue reconocida entre las primeras historiadoras del arte que estudiaron el arte prehispánico y realizó el primer estudio de las fuentes que tratan del arte del antiguo Perú incluyendo tanto las obras de las crónicas virreinales y la de los viajeros de los siglos XVIII y XIX, como de los arqueólogos del siglo XX.

Sin embargo, estas obras - como otras posteriores-si bien amparan la posición de que existieron artistas en el antiguo Perú no abordan el problema medular del proceso artístico, o la diferencia entre artistas o artesanos; en muchos casos se va a catalogar a ambos en el mismo sentido; en otros casos, los van a mencionar a todos sólo como artesanos. En líneas generales ha habido un vacío entre los especialistas en no profundizar en el estudio del arte del Perú antiguo y darle su justo sitial. Llama la atención por ello que no se denomine claramente a la producción plástica y arquitectónica del antiguo Perú como arte. 


\section{Al ENCUENTRO DE UNA COMPRENSIÓN ESTÉTICA Y FORMAL}

La obra plástica y su crítica son propias del estudio de la estética y de la historia del arte. Cabe recordar aquí que la historia del arte pertenece a las ciencias humanas, disciplina científica que se apoya en otras para arribar a sus conclusiones; la historia del arte estudia la producción artística y está ligada desde todas las épocas al espíritu de su productor: el artista que en todos los tiempos inclusive en la actualidad, realiza su obra como reflejo de la sociedad que le tocó vivir, bajo tendencias, estilos y manifestaciones plásticas diversas.

Y si bien la obra de arte es también un artefacto arqueológico, histórico y antropológico, ello no invalida su carácter estético. Por supuesto no toda pieza arqueológica puede ser considerada obra de arte, los objetos de uso cotidiano no lo eran. Sí, las que iban dedicadas al culto y que tuvieron un especial cuidado en su realización total; por tanto la obra de arte en el antiguo Perú es una obra de culto plástica. Esta aseveración ya la manifestaba el investigador argentino César Sondereguer en su obra Manual de estética precolombina: tesis hermenéutica (2002). A esta denominación de obra de culto plástica, debo añadir el rol de medio de comunicación visual y el de comunicación religiosa entre el oferente y la divinidad representada por la propia pieza de arte.

Toda obra de arte del antiguo Perú tiene un fundamento mítico, religioso, ceremonial y comunicante. Lo importante no es el soporte de la obra sino el significado de lo representado. Toda obra de culto plástica debe llevar una ornamentación simbólica pudiendo ser tanto figurativa como abstracta, donde el ornamento no va a ser un mero adorno, sino el portador de una carga significante. Al mismo tiempo, tal ornamento simbólico-ritual va a conectar a la divinidad con quien la otorga en el rito. Es decir me conecto con los dioses a través de tal o cual representación simbólica que está presente en la pieza. Pero también la pieza misma, ya de por sí puede ser simbólica, como ejemplo las esculturas totémicas de felinos, representaciones de chakanas, arquitecturas sacras, etc.

El crítico de arte Juan Acha asegura en su libro Las Culturas estéticas de América Latina: (reflexiones) que: «las estéticas precolombinas, como muchas otras del mundo, son ajenas a la belleza y al naturalismo, ideales renacentistas» (Acha 1993: 28). Efectivamente las culturas de la América antigua eran ajenas a los parámetros estéticos naturalistas que llegaron en el caso del Perú con los españoles. Pero se debe considerar que cada pueblo, cada cultura, ha tenido sus propios cánones de belleza, y no sólo las que provienen del renacimiento, del barroco $u$ otros. Todos ellos son modelos ajenos a la realidad prehispánica, y ya es hora de tomar nuestros propios referentes al momento de realizar los análisis históricos artísticos del antiguo Perú.

Estos referentes a los cuales me refiero están basados en los principios básicos que animan la distribución del espacio en la cosmovisión andina, como son las relaciones de dualidad (desdoblamientos, oposiciones y simetrías), tripartición y cuatripartición, los cuales van a servir al artista creador en la proyección y desarrollo visual de la obra misma.

En el caso de la dualidad, por citar algunos ejemplos se puede hablar de imágenes compuestas en base a simetrías, módulos repetitivos, como se aprecia en la Estela de Raimondi de la cultura Chavín (Fig. 1), si pasamos una línea central y horizontal sobre esta pieza, obtendremos a cada uno de sus lados simetría en su ejecución. También la dualidad-oposición se muestra en los opuestos cromáticos de la oposición entre lo claro y lo oscuro, o el enfrentamiento de los pares de colores complementarios, como el rojo y verde en el arte textil o combinaciones contrastantes como el rojo, amarillo y negro en los uncus o camisas masculinas incas (Fig. 2).

Bajo el referente de la tripartición, el espacio horizontal se hallaba dividido en tres planos: el Hanan Pacha (mundo de arriba), el Kay Pacha (mundo del centro, lo terrenal) y el Uku Pacha (mundo de adentro, de abajo). Símbolo máximo de esta tripartición es el signo escalonado andino, por ejemplo. Otro modelo de tripartición es la representación de una trilogía de deidades totémicas con el águila, cóndor o aves rapaces como dominantes del mundo de arriba, el felino como dominante del mundo terrestre y la serpiente que habita en el mundo subterráneo. 


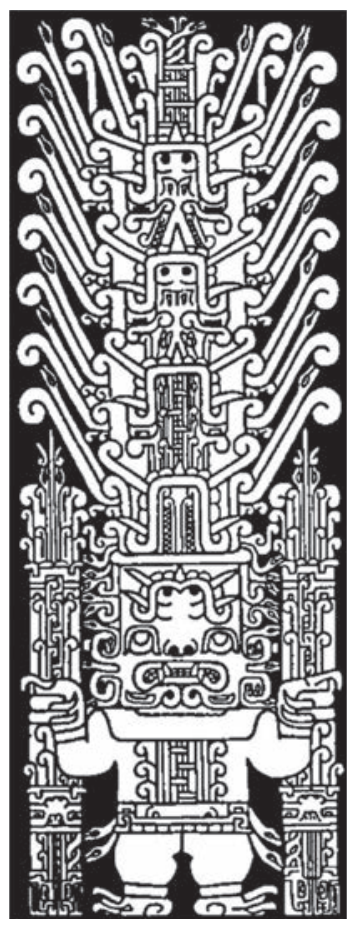

Figura 1. Estela de Raimondi (Dibujo de Evaristo Chumpitaz).

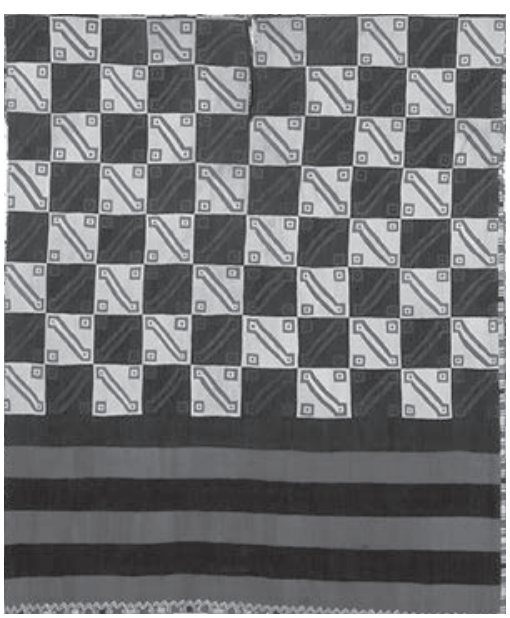

Figura 2. Uncu inca.

Fotografía: The Textile Museum (USA).
El arqueólogo Daniel Morales Chocano plantea que «[...] las tres plataformas y tres plazas que forman la pirámide truncada del centro ceremonial de Pacopampa, forman la estructura material primaria vinculada a la división tripartita del mundo social en el orden: inferior, medio y superior, cada uno de ellos diferenciados por las representaciones iconográficas muy importantes para entender el significado de cada uno de los espacios o plataformas» (Morales 1995: 86). En la plataforma inferior de Pacopampa aparece un dintel con representaciones de dos serpientes frente a frente; en la plataforma intermedia se ha registrado la presencia de dos monolitos de jaguares, macho y hembra; mientras que, en la plataforma superior en el dintel de entrada aparecen dos aves frente a frente. Este es un ejemplo de un canon arquitectónico en el cual se aprecia la tripartición del espacio y al mismo tiempo la dualidad del mismo, por la presencia de parejas de animales totémicos en oposición y complementariedad.

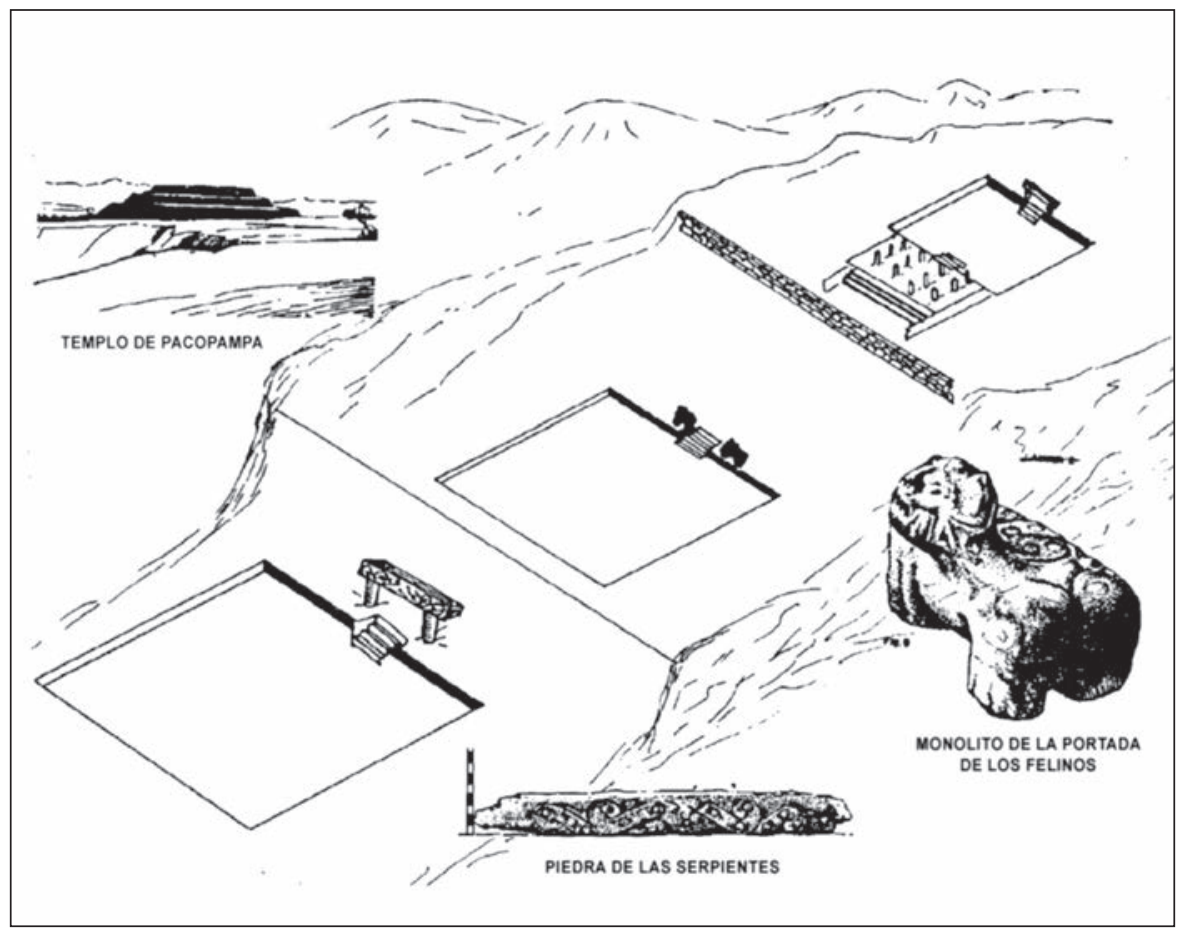

Figura 3. Templo de Pacopampa. Fuente: Daniel Morales Chocano. 
Los artistas del antiguo Perú van a aplicar la tripartición en la composición, en la distribución espacial de los diseños, en la edificación de arquitecturas, esculturas, en la cerámica, en el tejido, Etc. Este espacio tripartito simbólico, marca un dinamismo visual-estructural de conexión hacia arriba y hacia abajo, también de forma concéntrica o de un lado hacia otro. Por citar otro ejemplo en la Fig. 4. podemos apreciar el modo compositivo basado en la referencia de la tripartición en chuas o platos incas de cerámica. Nada es al azar en la creación artística en el antiguo Perú, el manejo del espacio visualmente responde a los principios del pensamiento religioso del artista ancestral.
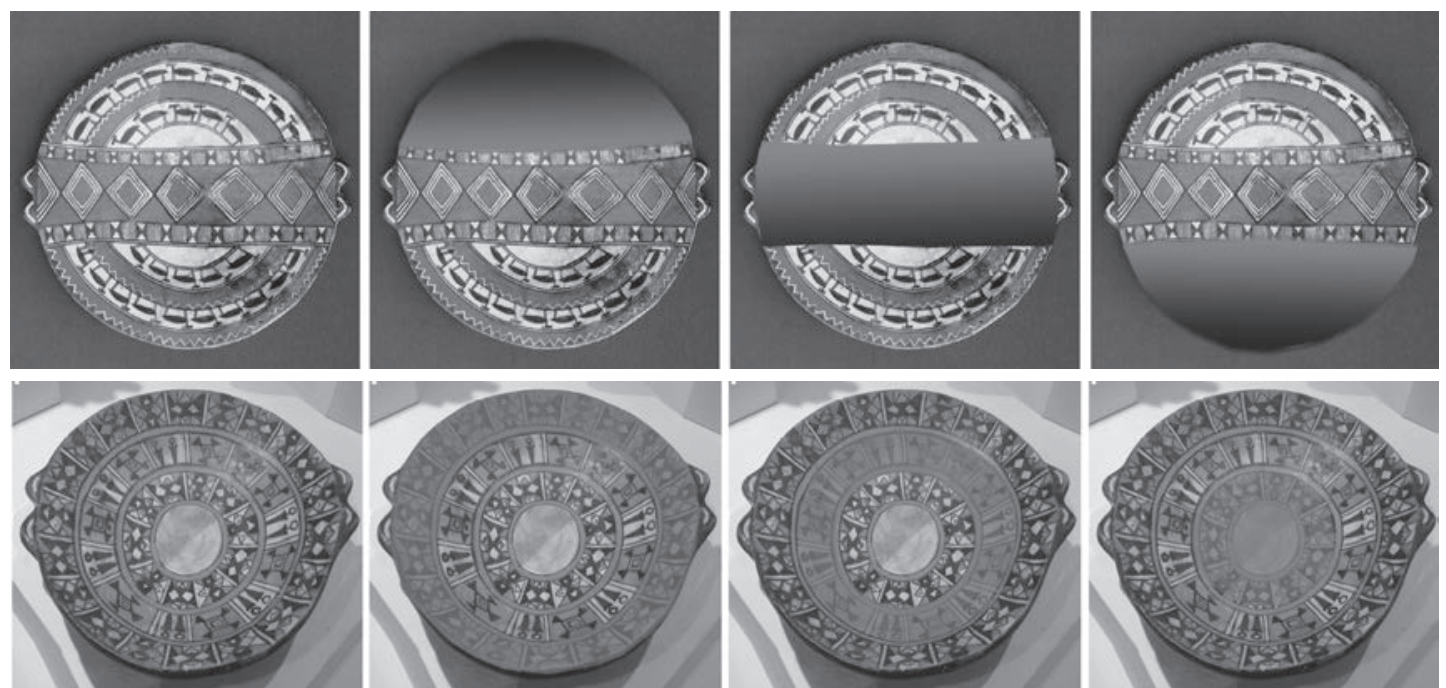

Figura 4. Platos chuas incas, se aprecia el referente de la tripartición del espacio en la distribución visual de los diseños. Colección del MNAAHP.

Respecto al referente de la cuatripartición, se trata del patrón de división andino por antonomasia, que se genera por una segunda bipartición. Lo encontramos expresado tanto en la división del espacio como en la del tiempo. El mejor ejemplo histórico es la organización misma del Tahuantinsuyo en cuatro «suyos» o cuadrantes. También lo podemos aplicar en tejidos como este diseño Chimú de la figura 5; pero además, el artista no sólo ha creado una imagen que corresponde a la cuatripartición del espacio sino también a representado a las divinidades que sostienen el pensamiento religioso en el cual cree y se atiene.

De otro lado, acerca del naturalismo hay una marcada incidencia en señalar que la obra plástica del antiguo Perú estuvo orientada a la abstracción de las formas, al uso de representaciones simbólicas e ideográficas. Es cierto que se ejecutaron manifestaciones artísticas bajo dichos parámetros, pero también es cierto que se efectuó numerosas piezas naturalistas y casi

Figura 5. Detalle de bolsa Moche (Museo Precolombino de Chile). Felinos rodeando a un sacerdote. Nótese la división cuatripartita en la composición de la imagen.

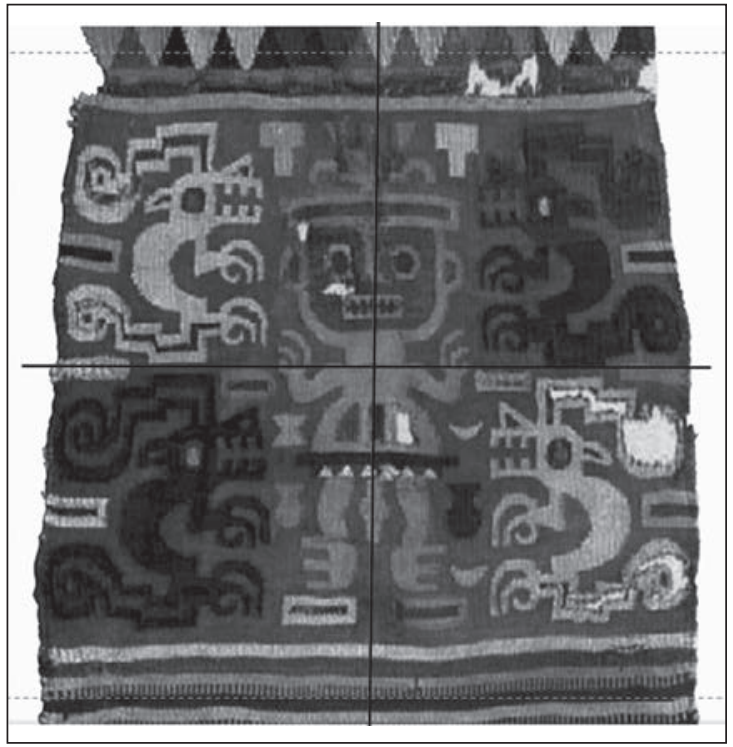


realistas; basta citar algunas muestras naturalistas mochicas, de la fauna sagrada y los denominados «huacos retratos» (Figs. 6 y 7).

Y ya sean obras plásticas de corte naturalista, figurativo, abstracto-figurativo, abstracto-geométrico, simbólico, etc.; todas subyacen al mismo intrínseco corpus de la cosmovisión andina y su división del tiempo y del espacio, aplicado con un lenguaje plástico particular, bajo el estilo de cada una de las culturas del Antiguo Perú. A ello se va a sumar los conceptos de integración y de sustitución

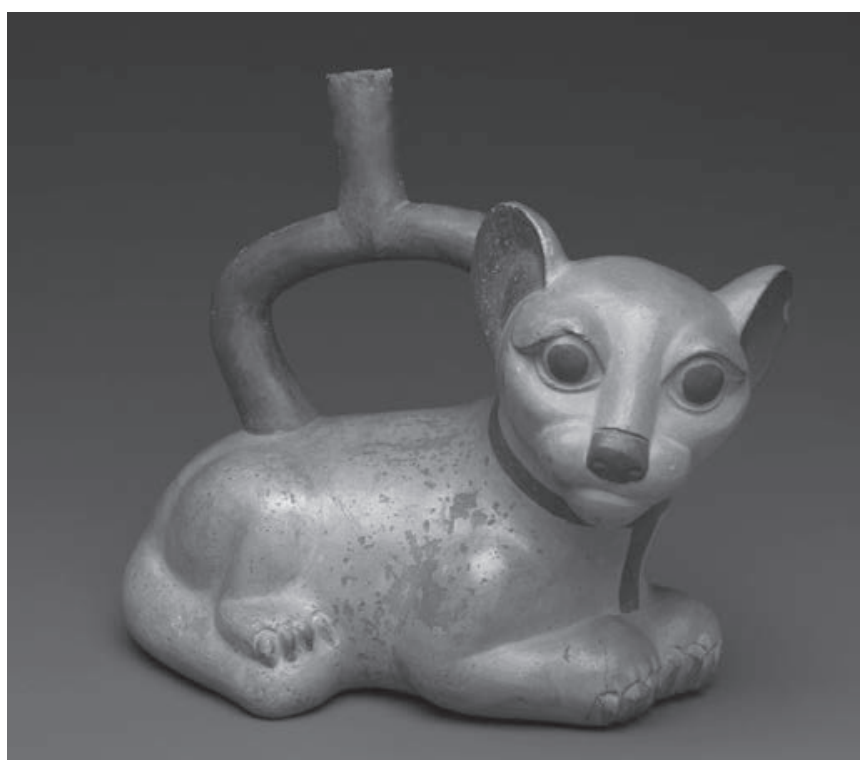

Figura 6. Puma moche. Fotografía: Museo Voelkerkunde (Alemania).

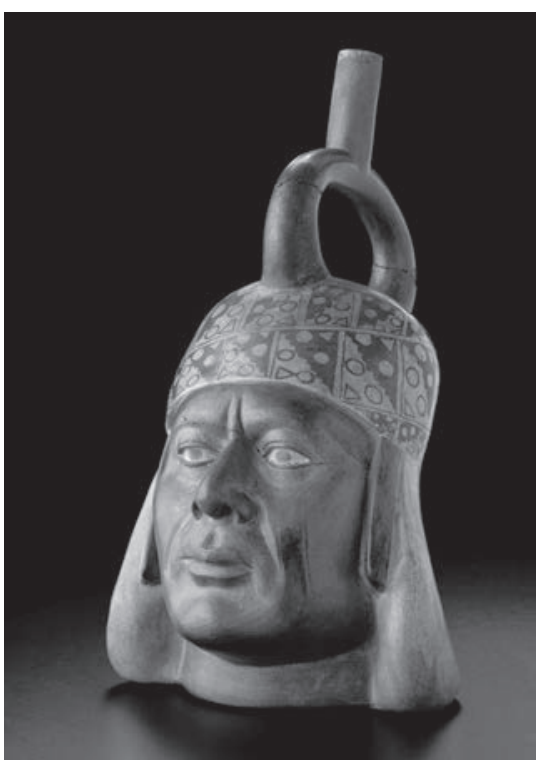

Figura 7. Huaco retrato moche. Fotografía: The Art Institute of Chicago, Illinois (USA)

de elementos para elaborar unos seres más poderosos y con esencias sobrenaturales que exceden a aquellas que les corresponden en el mundo real (Choque Porras 2009: 20). Este concepto de integración también se va a notar en la integración de urbanismo, arquitectura y paisaje como en el caso de Machu Picchu. Este sistema conceptual de pensamientos visuales, míticos, religiosos, políticos y sociales, que fue evolucionando a través del tiempo y las culturas, tuvo en la época inca un cohesionador de ideas y pensamientos estéticos. Evidentemente este sistema conceptual fue producto de una elaboración intelectual y altamente expresiva.

En todas las grandes culturas del antiguo Perú se manifestó la búsqueda consciente de la sensibilidad o gusto estético y de la belleza, entendida por sus propios cánones y diseños. Los artistas en el antiguo Perú elaboraron diversos objetos destinados al ritual y para los gobernantes y sacerdotes que dirigían ese ritual; objetos que no sólo eran dedicados a sus dioses, sino como ya he señalado, se convirtieron en piezas artísticas que constituían la propia representación del dios o la vinculación directa con las divinidades. Así, el artista andino transformó la materia para recrear todo en lo cual participaba y creía, el resultado: una obra de arte de gran poder visual, religioso y portador de conocimiento.

\section{EL ARTISTA ANDINO Y LA CREACIÓN}

A largo del desarrollo de la cultura peruana los mejores ceramistas de una comunidad, los mejores tejedores, metalúrgicos, picapedreros, escultores, arquitectos, etc., fueron asimilados al servicio de los templos. Se creo así una división social del trabajo, y de los servicios. Es decir, la existencia de sa- 
cerdotes y artistas dependía de los excedentes de la producción logrados por los campesinos a partir de los cuales también tuvieron lugar posteriores divisiones del trabajo, tales como el intercambio de productos agrícolas por productos manufacturados hechos por los artesanos, la minería, entre otros (Lumbreras 1974: 99-ss.)

Es innegable la especialización de una minoría dedicada a las labores artísticas, que debió estar en un nivel intermedio en la estructura social. Considerando el volumen y calidad de su producción debieron existir artistas y artesanos de dedicación total a sus tareas, sus obras eran dirigidas para el consumo local y para el intercambio. Coexistieron, pues, productores y dirigentes-creadores, los primeros dedicados a repetir modelos establecidos y creados por los segundos, pero ambos supervisados por la casta sacerdotal, sin que esto signifique que no surjan algunas arbitrariedades del artista prehispánico y por tanto comiencen a variar los motivos en el arte, que posteriormente pudieran devenir en un estilo. Desde tiempos inmemoriales los artesanos y artistas vivían en los talleres o cerca de ellos, por ende estaban cerca del poder. Los primeros artistas autores debieron ser por ello, los propios chamanes y sacerdotes encargados principales de los ritos.

Dado que la pieza artística del Antiguo Perú no tuvo el mismo fin que tuvo en otras latitudes -es decir, como objeto de contemplación- dichas creaciones vienen a ser obras de culto plástica, arte comprometido con un pensamiento ideológico; cuyo proceso habría pasado por los siguientes pasos:

1. La concepción y profunda creencia del artista andino de una cosmovisión particular, orientada e instaurada por una clase sacerdotal.

2. Observación y aprehensión de la naturaleza, de su flora, fauna, geografía y entes astrales que constituyen su mundo religioso. El artista andino es un profundo observador del comportamiento de animales sagrados, de las formas de la naturaleza y de los entes siderales. El artista va y visualiza las características y fortalezas del comportamiento de estos entes reales sobredimensionando muchas veces dichas posibilidades.

3. El traslado de ese pensamiento mágico-religioso a una proyección visual inicial que representará lo que el mito narraba (primeros bosquejos).

4. Posteriores ensayos hasta llegar al modelo final, ya sea representación naturalista, esquemática o abstracta, de acuerdo al estilo de cada cultura. En algunos casos, la imagen o diseño puede ser realizada también de forma rápida, lo cual no desacredita el valor de la creación artística.

5. Supervisión de la nueva representación por el sacerdote local y/o dirigentes políticos.

6. Traslado y adecuación de la imagen a un soporte material y a un genero plástico.

Vemos cómo en este proceso el artista andino ha resuelto la representación formal imaginándose el mito, trasladando los iconos que va recreando a un soporte de manera simbólica o de forma esquemática; es así que con pocas imágenes debe representar las historias míticas, o las deidades sobrenaturales y adecuarlas al soporte elegido.

La imagen va a ser el resultado de un pensamiento religioso, pero en ese proceso se halla la cualidad creadora de representación, que parte de un estilo ya definido por su propia cultura. Es decir, «los iconos no narran el mito sino son consecuencia de ello, es el arte que a través de convenciones codifica el mito» (Vargas s/f [en línea]).

El mundo animista en el cual se halla el artista andino - productor y dirigente creador- se manifiesta en la representación plástica; y la sociedad que cobija tales creencias ve en esta pieza de culto artística la seguridad y garantía de la conservación de su propia esencia social, política, religiosa y el convencimiento de su poder terrenal y el del «mundo de adentro» o de abajo como quiera llamársele. Ejemplo de ello, lo constituyen las imponentes construcciones incas; las pirámides truncadas de la costa norte peruana; Kuelap, Sipán, los mausoleos y tumbas que cobijaron a los grandes señores del pasado, una orientación espiritual que apuntó a la eternidad en el tiempo. Así, la duración ilimitada de la vida solo se podía alcanzar mediante la materialización arquitectónica pétrea, invencible ante el tiempo y el espacio. 
De otro lado, en las culturas del antiguo Perú no aparece nunca la firma del hacedor de la producción plástica. El hecho de llevar o no firma de su autor, no invalida el logro de una gran producción plástica. No hace falta la firma o sello del artista, ello no tiene razón de ser porque la pieza artística no es considerada por las diversas culturas como de pertenencia de su productor o creador, le pertenece a la propia deidad, representada o conectada con la misma pieza, le pertenece al Estado generador de la producción estatal artística.

Van a ser los artistas en el antiguo Perú los intermediarios, entre el conocimiento de lo sagrado monopolizado por la élite sacerdotal y de cuyo manejo e interpretación emana su poder real; con la propia divinidad manifestada en el felino, la serpiente, las aves mágicas, el sol, la luna, las estrellas, los apus y todo ente que dentro de su pensamiento controle las fuerzas de la naturaleza; donde el canal o vía de comunicación es la propia pieza de culto plástica. La élite teocrática cuenta con la capacidad dirigir el proceso de creación del arte en el período prehispánico, tiene en el artista de este tiempo un artífice y creador de dioses, de imágenes, de iconografía, representaciones visuales de profundo contenido simbólico, que configuran la cosmovisión y pensamiento de las diversas sociedades del Antiguo Perú.

\section{Agradecimiento}

El presente artículo está basado en la ponencia del mismo nombre presentada en el XVII Congreso Peruano del Hombre y la Cultura Andina y Amazónica, realizado en la Universidad Nacional Faustino Sánchez Carrión (Huacho-Lima) en agosto del 2011. Dedico este trabajo al arqueólogo e historiador peruano, Dr. Federico Kauffmann Doig quien, siempre con sus sabios consejos y apreciaciones, viene apoyando a quienes nos dedicamos a investigar sobre nuestro pasado para ponerlo en su justo sitial en el presente.

\section{BiBLIOGRAFÍA}

CARRIÓN, Rebeca

2005 La religión en el Antiguo Perú. Lima: INC.

cossío, Felipe

1949 Arte del Perú precolombino: Volumen 1. Lima: Fondo de Cultura Económica

CHOQUE, Alba

2009 La imagen del felino en el arte del Antiguo Perú. Lima: Fundación San Marcos para el Desarrollo de la Ciencia y la Cultura.

KAUFFMANN, Federico

2011 «Los dioses andinos: dioses del sustento». Arqueología y Vida, 4: 245-291. Trujillo: Museo de Arqueología, Antropología e Historia.

LUMBRERAS, Luis G.

1974 Visión arqueológica del Perú milenario. Lima: Milla Batres.

MILLA, Zadir

1991 Introducción a la semiótica del diseño andino precolombino. Lima: Eximpress S.A.

MORALES, Daniel

1995 «Estructura dual y tripartita en la arquitectura de Pacopampa y en la iconografía de Chavín y Nazca». Revista del Instituto de Investigaciones Histórico Sociales 1: 83-102. Lima: UNMSM.

SACO, María Luisa

1978 Fuentes para el estudio del arte peruano precolombino. Lima: Retablo de Papel Ediciones.

STASTNY, Francisco

1967 Breve historia del arte en el Perú: la pintura precolombina, colonial y republicana. Lima: Editorial Universo.

VARGAS, David

s/f. A Propósito de las Interpretaciones del Arte del Antiguo Perú. <http://www.arqueologiadelperu.com.ar/ historia_arte_03.htm> [Consulta: 9 de agosto 2013]. 